Article

\title{
Impact of Women Obesity and Obesity Severity on Live Birth Rate after In Vitro Fertilization
}

\author{
Cécile Brunet ${ }^{1}$, Safa Aouinti ${ }^{2}$, Fanchon Huguet ${ }^{3}$, Valérie Macioce ${ }^{2} \mathbb{D}$, Noémie Ranisavljevic ${ }^{1}$, \\ Anna Gala ${ }^{4}$, Antoine Avignon ${ }^{3,5}$, Thibault Mura ${ }^{6}$ and Ariane Sultan ${ }^{3,5, *}$
}

1 Reproductive Medicine Unit, Univ Montpellier, CHU Montpellier, 34295 Montpellier, France; c-brunet@chu-montpellier.fr (C.B.); n-ranisavljevic@chu-montpellier.fr (N.R.)

2 Clinical Research and Epidemiology Unit, Univ Montpellier, CHU Montpellier, 34295 Montpellier, France; s-aouinti@chu-montpellier.fr (S.A.); v-macioce@chu-montpellier.fr (V.M.)

3 Nutrition Endocrinology Diabetes Department, Univ Montpellier, CHU Montpellier, 34295 Montpellier, France; fanchon.huguet@hotmail.com (F.H.); a-avignon@chu-montpellier.fr (A.A.)

4 Reproductive Biology Unit, Univ Montpellier, CHU Montpellier, 34295 Montpellier, France; a-gala@chu-montpellier.fr

5 PhyMedExp, INSERM, CNRS UMR, University of Montpellier, CHRU Montpellier, 34295 Montpellier, France

6 Department of Biostatistics, Epidemiology and Public Health, Univ Montpellier, CHU Nimes, 30029 Nimes, France; thibault-mura@chu-nimes.fr

* Correspondence: a-sultan@chu-montpellier.fr; Tel.: +33-467-338-964

Received: 19 May 2020; Accepted: 24 July 2020; Published: 28 July 2020

check for updates

\begin{abstract}
Access to in vitro fertilization (IVF) for obese women varies across centers, and the impact of obesity on IVF outcomes is widely discussed. We assessed the impact of obesity and its severity on live birth rate (LBR) after IVF. We included women treated for IVF in our center. Data were prospectively collected in the BabySentry ${ }^{\mathrm{TM}}$ software. LBR per cycle and cumulative LBR including all attempts of the couple were calculated, considering transfer of both fresh and frozen embryos. Of 1588 included women (2379 controlled ovarian stimulations), 70.2\%, 19.5\%, 7.9\%, and 2.4\% were normal-weight, overweight, class I obesity, and class II/III obesity, respectively. For each cycle, LBR did not differ according to BMI category. Adjusted odds ratios (95\% confidence intervals) for obtaining a live birth at the first cycle were $1.11(0.78-1.58)$ for overweight, $1.17(0.70-1.95)$ for class I obese, and 1.05 (0.48-2.31) for class II/III obese women, as compared with normal-weight women. Similarly, no significant associations were found at cycles 2, 3, and 4. Cumulative LBR increased with the number of cycles, independently of the BMI class ( $p$ log-rank $=0.91)$. After adjustment, obesity status did not impact significantly the miscarriage rate, regardless of the cycle. In conclusion, neither women obesity nor its severity impacted the cumulative LBR after IVF.
\end{abstract}

Keywords: assisted reproductive technology; in vitro fertilization; live birth; obesity; body mass index; controlled ovarian stimulation

\section{Introduction}

Obesity, a major problem of public health, intervenes at different levels on the reproductive function. It is associated with increased conception time [1] and decreased fecundity [2]. Although the number of obese women in demand of assisted reproductive technology (ART) is unknown, this is a common situation in clinical practice.

According to the NICE guidance on fertility problems, women have to be informed that BMI should ideally be in the range $19-30 \mathrm{~kg} / \mathrm{m}^{2}$ before starting assisted reproduction, and that a BMI outside this range is likely to reduce ART procedures success [3]. A BMI greater than $35 \mathrm{~kg} / \mathrm{m}^{2}$ is often considered as a contraindication to ART [4,5], and many centers around the world are denying 
access to ART program for obese women, in particular in vitro fertilization (IVF). In France, there is no legislation and each center has its own practices.

Beyond access to IVF, the impact of obesity on oocytes number, clinical pregnancy rate, and live birth rate is also widely discussed [6-9]. Most studies investigating the impact of obesity on IVF results have not specifically assessed the impact of obesity severity. Given the limited access of obese women to IVF, few studies included women with a BMI greater than $35 \mathrm{~kg} / \mathrm{m}^{2}$. Most studies considered only fresh embryo transfer $[6,10-13]$ or only the first stimulation attempt $[9,14]$. Thus, the impact of obesity on IVF results remains unclear, in particular according to the grade of obesity, and studies taking into account both the entire embryonic cohort (fresh and frozen or vitrified embryos) and all stimulation attempts are lacking.

Therefore, this study aimed to assess the impact of obesity and obesity severity on the live birth rate after IVF+/-ICSI in a French cohort. We considered both the live birth rate per cycle and the cumulative live birth rate including all the attempts of the couple.

\section{Experimental Section}

\subsection{Population and Design}

This retrospective monocentric cohort study was conducted in the Reproductive Medicine Unit of Montpellier University Hospital between April 2011 and December 2017, among women treated for IVF (+/-ICSI). In this center, BMI category is not an exclusion criteria for access to IVF. We excluded from our analyses non-nulliparous women in the current couple, those undergoing IVF for pre-implantation genetic diagnosis, those for whom cycles were cancelled before oocyte pickup, those who benefited from 4 stimulations cycles in other centers, and those with BMI $<18.5 \mathrm{~kg} / \mathrm{m}^{2}$.

\subsection{IVF Procedure}

We chose agonist or antagonist protocol for controlled ovarian stimulation (COS) according to the infertility cause. Gonadotrophins used were r-FSH or HMG according to the woman hormonal profile with a starting dose adapted to age, ovarian reserve and BMI. Oocyte pick-up was performed $36 \mathrm{~h}$ after triggering with HCG when at least 3 follicles reached $17 \mathrm{~mm}$. Embryo transfer was performed with ultrasonoguidance at day 3 or 5 after oocyte pick-up. Luteal support was obtained with vaginal progesterone at $600 \mathrm{mg} /$ day starting on the oocyte pick-up day until the $\beta H C G$ ( $\beta$-human chorionic gonadotropin) test day. Clinical pregnancy was confirmed with transvaginal ultrasonography at 6 gestational weeks after two positive $\beta$ HCG tests. For frozen embryo transfer, women were prepared with a natural cycle when they were ovulatory and with a substituted cycle when they were not. The substituted cycle was obtained with oral natural estrogen and vaginal progesterone was introduced when endometrium thickness reached $7 \mathrm{~mm}$.

\subsection{Data Collection}

All data were prospectively collected in the BabySentryTM software (Babysentry Ltd., San Pedro, CA, United States), a central database electronic medical record. For each IVF initiated, we collected (i) basic patients characteristics including BMI, infertility etiology, baseline ovarian reserve parameters at day 3 of the cycle, COS parameters, (ii) stimulation results (number of oocytes obtained, number of embryos obtained on second day), (iii) results of transfer (number of embryo(s) transferred, day of transfer, number of frozen embryo(s)) (iv) modality of the attempt (IVF or ICSI) and (v) outcome of IVF (live birth or miscarriage). Cycle 1 was defined as the first IVF cycle that the patient starts in our center, cycle 2 as the second cycle that the patient starts in our center, and so on. Primary outcome was the live birth rate. 


\subsection{Statistical Analysis}

Continuous variables were described with means and standard deviation or median and interquartile range. Categorical variables were described with frequencies. Missing data were not taken into account to calculate frequencies. Women were divided into five groups according to the World Health Organization (WHO) classification cut-points: normal-weight $\left(18.5-24.9 \mathrm{~kg} / \mathrm{m}^{2}\right)$, overweight $\left(25-29.9 \mathrm{~kg} / \mathrm{m}^{2}\right)$, class I obesity $\left(30-34.9 \mathrm{~kg} / \mathrm{m}^{2}\right)$, class II obesity (BMI $35-39.9 \mathrm{~kg} / \mathrm{m}^{2}$ ) and class III obesity (BMI $\geq 40 \mathrm{~kg} / \mathrm{m}^{2}$ ). Class II and III obesity were gathered due to the small number of women. Normal-weight women were the reference group.

Patients' characteristics and ovarian simulation methods were compared according to BMI category using ANOVA or Kruskal-Wallis test for quantitative variables, and with chi-square analysis or Fisher's exact test for categorical variables. To assess the impact of BMI on live birth rate or occurrence of miscarriage, logistic regressions were used to calculate raw and adjusted odds ratios (OR) along with their $95 \%$ confidence intervals (CI). OR were adjusted on potential confounding factors: Age, smoking status, infertility causes and anti-Müllerian hormone (AMH) plasmatic level.

The cumulative live birth incidence curve according to the BMI class was constructed with Kaplan-Meier curve using the cycle as unit of time. Women who were not pregnant in a cycle and did not carry out other stimulation cycle later were censored from this point. Women who were followed-up in our center only from the 2 nd, 3rd, or 4th cycle (without live birth resulting from previous cycles) were entered into the analysis using truncation method on the left. The curves were compared between the 4 BMI classes using a log-rank test. Statistical bilateral significance threshold was set at 5\%. All statistical analyses were performed using SAS ${ }^{\circledR}$ Enterprise Guide (SAS Institute, Cary, NC, USA) version 7.12.

\section{Results}

\subsection{Population Characteristics}

Of 2239 women treated in the study center, representing 4044 COS, 1588 eligible patients (1279 COS) were included (Figure 1). Among them, 1115 had a normal BMI (70.2\%), 309 were overweight $(19.5 \%)$, and 164 were obese (10.3\%). Of these, 126 women had class I obesity $(77 \%)$ and 38 had grade II/III obesity (23\%). Table 1 shows women characteristics according to BMI category. Mean age was similar between subgroups of women. Distribution of infertility etiology was significantly different regarding BMI, with a higher prevalence of dysovulation and polycystic ovarian syndrome (PCOS) among obese women.

\subsection{COS Characteristics}

Characteristics and results of COS for cycle 1 and 2 according to BMI classes are presented in Table 2. The protocol used for COS was similar whatever the BMI. However, both starting and total dose of gonadotrophins used for stimulation were significantly higher in obese than in normal-weight women, for both cycle 1 and cycle 2. Regarding results of cycles 1 and 2, number of either oocytes collected or mature oocytes or embryos obtained at day 2 was comparable across all BMI classes. However, during the first cycle, the number of fresh embryos transferred significantly decreases with increasing BMI classes. Further, during the second cycle, the total number of transferred embryos was lower for higher BMI classes.

Results for cycle 3 and 4 showed no difference. 


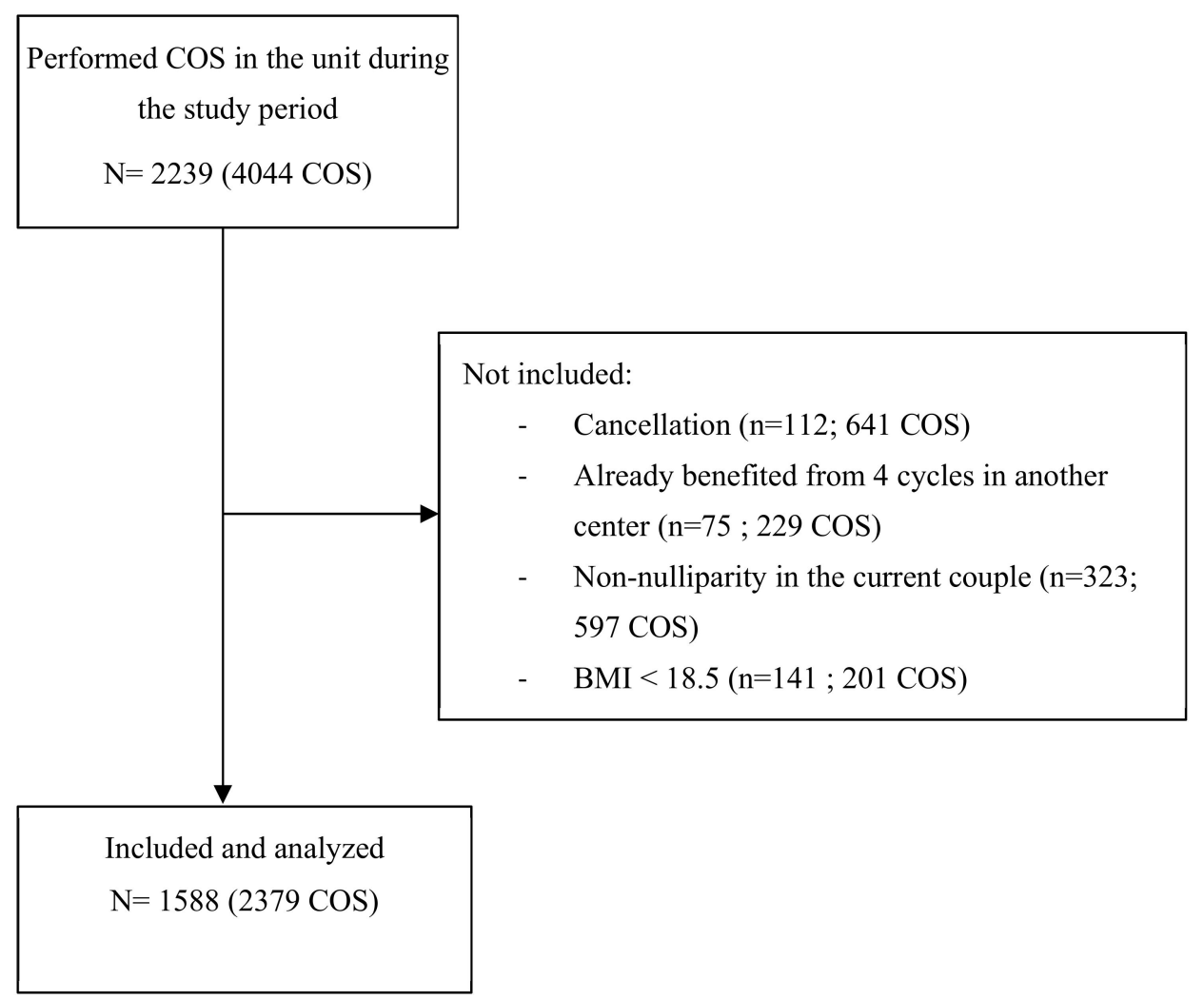

Figure 1. Flow chart. COS: controlled ovarian stimulation.

Table 1. Characteristics of Women Included in the Study According to Their BMI Class.

\begin{tabular}{|c|c|c|c|c|c|}
\hline Variables & $\begin{array}{c}\text { Normal } \\
\text { Weight } \\
(n=1115)\end{array}$ & $\begin{array}{l}\text { Overweight } \\
\qquad(n=309)\end{array}$ & $\begin{array}{l}\text { Class I Obesity } \\
\quad(n=126)\end{array}$ & $\begin{array}{c}\text { Class II/III } \\
\text { Obesity } \\
(n=38)\end{array}$ & $p$-Value \\
\hline Age (years) & $33.3 \pm 4.9$ & $32.6 \pm 5.6$ & $33.5 \pm 5.7$ & $32.7 \pm 4.8$ & 0.32 \\
\hline Smoking (\%) & 26.2 & 21.2 & 22.7 & 20 & 0.28 \\
\hline \multicolumn{6}{|l|}{ Infertility etiology } \\
\hline Dysovulation (\%) & 7.5 & 16.8 & 16.7 & 31.6 & $<0.001$ \\
\hline Tubal factor (\%) & 14.1 & 15.5 & 16.7 & 18.4 & 0.72 \\
\hline Endometriosis (\%) & 21.6 & 15.9 & 8.7 & 7.9 & $<0.001$ \\
\hline $\operatorname{PCOS}(\%)$ & 6.6 & 13.3 & 15.9 & 21 & $<0.001$ \\
\hline Male infertility (\%) & 55.7 & 57.3 & 63.5 & 65.8 & 0.25 \\
\hline Idiopathic (\%) & 13.5 & 9.1 & 10.3 & 0 & 0.015 \\
\hline Other (\%) & 1.5 & 1.9 & 1.6 & 0 & 0.91 \\
\hline \multicolumn{6}{|l|}{ Gestity and parity } \\
\hline Gestity & $0.48 \pm 0.98$ & $0.59 \pm 1.06$ & $0.57 \pm 1.00$ & $0.53 \pm 1.2$ & 0.26 \\
\hline Parity & $0.10 \pm 0.44$ & $0.11 \pm 0.43$ & $0.17 \pm 0.57$ & $0.05 \pm 0.23$ & 0.24 \\
\hline \multicolumn{6}{|l|}{ Ovarian reserve } \\
\hline $\mathrm{AMH}$ & $3.6 \pm 3.4$ & $4.1 \pm 4.5$ & $3.4 \pm 2.4$ & $4.7 \pm 3.8$ & 0.005 \\
\hline FSH & $7.5 \pm 4.5$ & $7.0 \pm 4.3$ & $6.6 \pm 1.7$ & $5.9 \pm 1.6$ & $<0.001$ \\
\hline
\end{tabular}

Data are means \pm standard deviations, or percentages. PCOS: polycystic ovarian syndrome; AMH: anti-Müllerian hormone; FSH: Follicle-stimulating hormone. 
Table 2. Characteristics of Controlled Ovarian Stimulation for the Two First Cycles by BMI Class.

\begin{tabular}{|c|c|c|c|c|c|c|c|c|c|c|}
\hline & \multicolumn{5}{|c|}{ Cycle 1} & \multicolumn{5}{|c|}{ Cycle 2} \\
\hline & $\begin{array}{l}\text { Normal Weight } \\
\quad(n=804)\end{array}$ & $\begin{array}{c}\text { Over-Weight } \\
(n=232)\end{array}$ & $\begin{array}{l}\text { Class I Obesity } \\
\quad(n=95)\end{array}$ & $\begin{array}{c}\text { Class II/III } \\
\text { Obesity }(n=35)\end{array}$ & $p$-Value & $\begin{array}{l}\text { Normal Weight } \\
\quad(n=406)\end{array}$ & $\begin{array}{c}\text { Over-Weight } \\
(n=102)\end{array}$ & $\begin{array}{c}\text { Class I Obesity } \\
\quad(n=47)\end{array}$ & $\begin{array}{c}\text { Class II/III } \\
\text { Obesity }(n=14)\end{array}$ & $p$-Value \\
\hline \multicolumn{11}{|l|}{ Protocol (\%) } \\
\hline Agonist & 44.7 & 50.4 & 45.3 & 40 & 0.41 & 37.9 & 42.2 & 44.7 & 42.9 & 0.73 \\
\hline Antagonist & 55.3 & 49.6 & 54.7 & 60 & & 62.1 & 57.8 & 55.3 & 57.1 & \\
\hline \multicolumn{11}{|l|}{$\begin{array}{c}\text { ART technique } \\
(\%)\end{array}$} \\
\hline IVF & 40.8 & 40.7 & 39.8 & 25 & 0.36 & 24.4 & 23.7 & 15.6 & 23.1 & 0.65 \\
\hline ICSI & 59.2 & 59.3 & 60.2 & 75 & & 75.6 & 76.3 & 84.4 & 76.9 & \\
\hline \multicolumn{11}{|l|}{ Gonadotrophin } \\
\hline Starting dose (UI) & $206 \pm 74$ & $199 \pm 72$ & $231 \pm 61$ & $236 \pm 75$ & $<0.001$ & $226 \pm 75$ & $223 \pm 76$ & $247 \pm 71$ & $261 \pm 78$ & 0.19 \\
\hline Total dose (UI) & $2138 \pm 850$ & $2158 \pm 884$ & $2449 \pm 774$ & $2624 \pm 992$ & $<0.001$ & $2275 \pm 871$ & $2307 \pm 909$ & $2689 \pm 972$ & $3138 \pm 1346$ & 0.009 \\
\hline Duration (days) & $10.3 \pm 1.3$ & $10.6 \pm 1.6$ & $10.4 \pm 1.4$ & $10.8 \pm 1.6$ & 0.05 & $10.1 \pm 1.4$ & $10.2 \pm 1.6$ & $10.6 \pm 1.9$ & $11.5 \pm 2.5$ & 0.009 \\
\hline $\begin{array}{c}\text { Number of } \\
\text { oocytes collected }\end{array}$ & $10.6 \pm 6.0$ & $10.7 \pm 5.9$ & $10.9 \pm 6.2$ & $10.8 \pm 6.1$ & 0.88 & $9.8 \pm 5.7$ & $10.3 \pm 5.4$ & $10.7 \pm 6.3$ & $8.7 \pm 5.0$ & 0.45 \\
\hline $\begin{array}{l}\text { Number of } \\
\text { mature oocytes } \\
\text { Number of }\end{array}$ & $5.1 \pm 5.8$ & $5.1 \pm 5.4$ & $5.3 \pm 5.9$ & $5.9 \pm 5.8$ & 0.62 & $5.7 \pm 5.1$ & $6.1 \pm 5.5$ & $6.5 \pm 4.9$ & $5.6 \pm 5.1$ & 0.66 \\
\hline $\begin{array}{l}\text { embryos obtained } \\
\text { at day } 2\end{array}$ & $5.8 \pm 4.4$ & $5.6 \pm 3.9$ & $5.0 \pm 4.1$ & $5.2 \pm 4.7$ & 0.31 & $5.2 \pm 3.9$ & $5.4 \pm 4.2$ & $4.0 \pm 3.3$ & $5.6 \pm 4.7$ & 0.19 \\
\hline $\begin{array}{l}\text { Number of fresh } \\
\text { transferred } \\
\text { embryos }\end{array}$ & $1.2 \pm 0.8$ & $1.1 \pm 0.8$ & $1.3 \pm 0.8$ & $0.9 \pm 0.9$ & 0.006 & $1.4 \pm 0.9$ & $1.4 \pm 0.9$ & $1.3 \pm 0.9$ & $1.2 \pm 0.8$ & 0.45 \\
\hline $\begin{array}{l}\text { Total number of } \\
\text { transferred } \\
\text { embryos }\end{array}$ & $1.9 \pm 1.2$ & $1.8 \pm 1.1$ & $1.8 \pm 1.2$ & $1.5 \pm 1.1$ & 0.04 & $2.0 \pm 1.3$ & $2.2 \pm 1.3$ & $1.6 \pm 1.3$ & $1.4 \pm 0.8$ & 0.006 \\
\hline
\end{tabular}

Data are means \pm standard deviations or percentages; ART: assisted reproductive technique; IVF: in vitro fertilization; ICSI: intracytoplasmic sperm injection. 


\subsection{Impact of Obesity on Live Birth Rate Per Cycle and on Cumulative Live Birth Rate}

For each cycle, the live birth rate did not differ according to BMI category (Figure 2). During the first cycle, the live birth rate/cycle was $34.7 \%$ in class I obese women, and $31.4 \%$ in class II/III vs. $31.5 \%$ in normal-weight women. In the second cycle, the live birth rate tended to be lower than in the first cycle in all BMI categories.

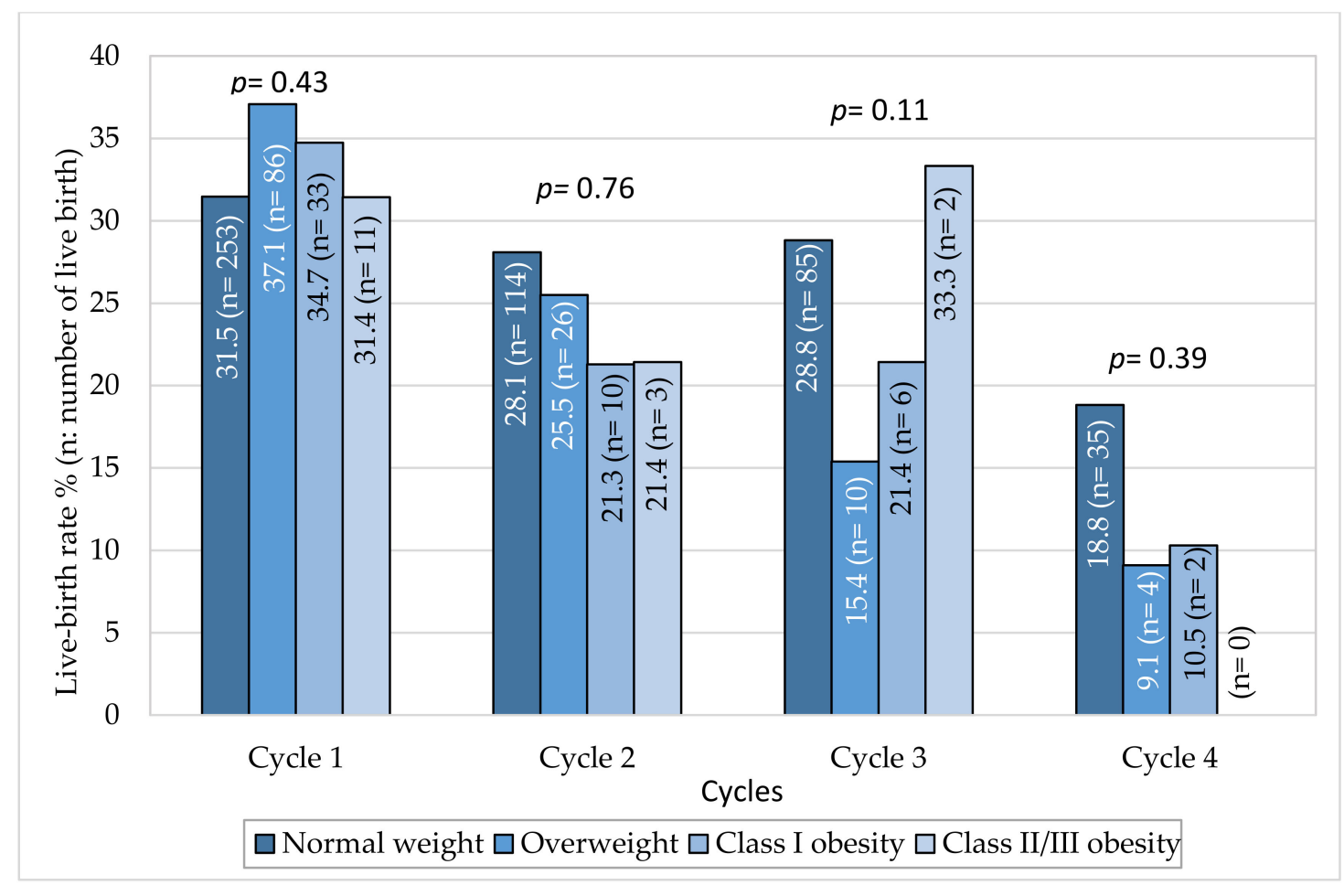

Figure 2. Live-birth rate by cycle and BMI class.

Adjusted OR for obtaining a first live birth by BMI class are shown in Table 3. After adjustment for age, smoking status, infertility causes and AMH plasmatic levels, neither obesity nor obesity severity affected significantly the chance to obtain a live birth, regardless of the cycle. When considering all women with BMI $\geq 25 \mathrm{~kg} / \mathrm{m}^{2}$, their chance to obtain a live birth was not significantly different from that of normal-weight women for each cycle, and overall for the 4 cycles (adjusted OR 0.90, CI 95\% $0.72-1.13, p=0.36$ ).

The cumulative live birth rate, defined as live birth rate at the end of the attempts, was represented for each BMI class (Figure 3). Cumulative live birth rate increased with the number of cycles, independently of BMI $(p$ log-rank $=0.91)$. 
Table 3. Adjusted Odds Ratios for Obtaining a First Live Birth by BMI Class.

\begin{tabular}{|c|c|c|c|c|c|c|c|c|}
\hline \multirow[b]{2}{*}{$\begin{array}{c}\text { BMI } \\
\text { Classes }\end{array}$} & \multicolumn{8}{|c|}{ Adjusted OR $[95 \% \mathrm{CI}] \ddagger$} \\
\hline & $\mathbf{N}$ & Cycle 1 & $\mathbf{N}$ & Cycle 2 & $\mathbf{N}$ & Cycle 3 & $\mathbf{N}$ & Cycle 4 \\
\hline $\begin{array}{l}\text { Normal } \\
\text { weight }\end{array}$ & 804 & 1 & 406 & 1 & 295 & 1 & 186 & 1 \\
\hline Overweight & 232 & $\begin{array}{c}1.11 \\
(0.78-1.58) \\
p=0.55\end{array}$ & 102 & $\begin{array}{c}0.83 \\
(0.47-1.46) \\
p=0.51\end{array}$ & 65 & $\begin{array}{c}0.45 \\
(0.20-1.03) \\
p=0.06\end{array}$ & 44 & $\begin{array}{c}0.44 \\
(0.12-1.56) \\
p=0.20\end{array}$ \\
\hline $\begin{array}{l}\text { Class I } \\
\text { obesity }\end{array}$ & 95 & $\begin{array}{c}1.17 \\
(0.70-1.95) \\
p=0.55\end{array}$ & 47 & $\begin{array}{c}0.68 \\
(0.29-1.55) \\
p=0.36\end{array}$ & 28 & $\begin{array}{c}0.97 \\
(0.36-2.64) \\
p=0.95\end{array}$ & 19 & $\begin{array}{c}0.59 \\
(0.11-3.11) \\
p=0.54\end{array}$ \\
\hline $\begin{array}{c}\text { Class } \\
\text { II/III } \\
\text { obesity }\end{array}$ & 35 & $\begin{array}{c}1.05 \\
(0.48-2.31) \\
p=0.90\end{array}$ & 14 & $\begin{array}{c}0.69 \\
(0.14-3.37) \\
p=0.65\end{array}$ & 6 & $\begin{array}{c}0.87 \\
(0.08-9.39) \\
p=0.91\end{array}$ & 1 & - \\
\hline
\end{tabular}

‡: Odd ratios adjusted by stimulation age, smoking status, infertility etiologies and AMH levels.

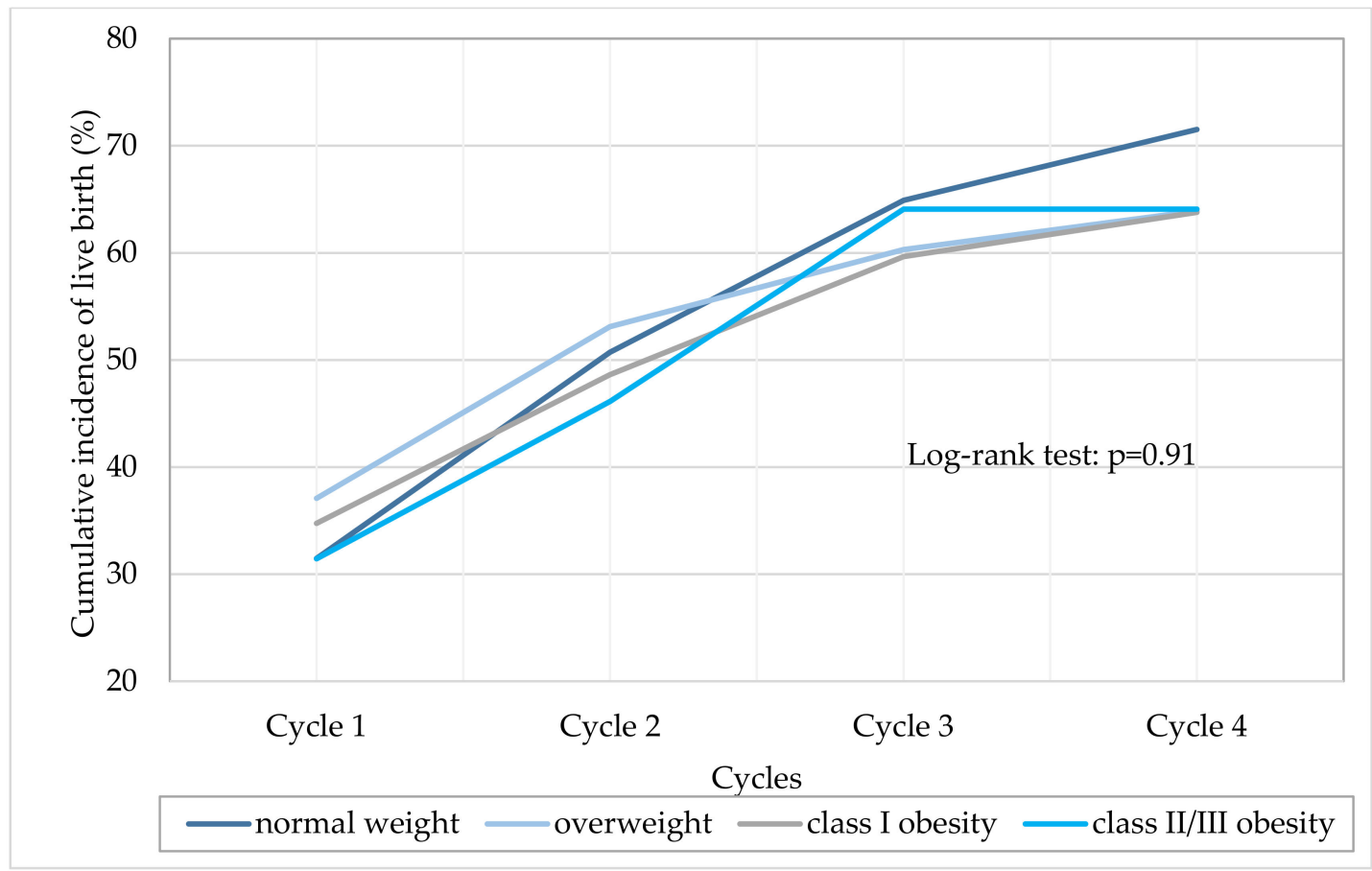

Figure 3. Cumulative incidence of live birth by BMI class.

\subsection{Impact of Obesity on Rank of Transfer, Fresh, or Frozen Embryo Transfer and Miscarriage}

For each cycle, live birth was mainly obtained after the first transfer, regardless of BMI. Indeed, median rank of embryo transfer to obtain a live birth was 1 for all cycles and all BMI classes (Table S1). Further, percentages of women with at least one fresh and frozen embryo transfer that resulted in live birth at each cycle were not significantly different according to BMI category. At cycle 1 , respectively $20.5 \%, 22.8 \%, 28.4 \%$, and $17.4 \%$ of women with at least one fresh embryo transfers $(p=0.29)$ and $13.8 \%$, $18.4 \%, 8.8 \%$, and $17.2 \%$ of women with at least one frozen embryo transfers ( $p=0.21)$ obtained a live birth for normal-weight, overweight, class I obese and class II/III obese women, respectively $(p=0.29)$ (Table S2).

Finally, we expressed the OR of miscarriage at the first clinical pregnancy for each BMI class compared to normal-weight women. BMI did not impact significantly the miscarriage rate, regardless of the cycle and after adjusting for confounding factors (age, smoking habits, infertility causes, and AMH plasmatic level) (Table S3). 


\section{Discussion}

This large cohort study showed that neither women obesity nor its severity affected IVF outcomes. Its originality lies in taking into account all stimulation attempts and both fresh and frozen embryos, whereas most studies considered only the first cycle or only fresh embryos [15]. We also assessed the rank of the transfer that allowed the live birth for each BMI class.

We found that neither obesity nor obesity severity do affect significantly the live birth rate regardless of the cycle, both on raw data and after adjustment for potential confounding factors. Indeed, cumulative live birth rate increased with the number of cycles, independently of BMI. Further, we showed that the live birth rate was higher during the first cycle of stimulation in all BMI classes. Despite fewer embryos transferred with increasing BMI, live birth at each cycle was mainly obtained after the first embryo transfer, regardless of BMI.

Data from the literature are not consensual regarding the effect of obesity and its severity on live birth rate. Indeed, some studies did not find any deleterious effect of BMI, with no significant difference in the live birth rate between normal-weight and overweight women [16,17], but also between normal-weight and obese women [7,18] and between BMI categories [19]. Likewise, Coyne et al. showed that gestational carriers' BMI does not impair reproductive outcomes including live birth rate [20]. On the contrary, other studies found a negative impact of obesity and of each of the grades of obesity on the live birth rate compared to normal BMI $[6,9,21]$, specifically in women under 35 years [22], and for obesity in general compared to reference BMI category [12]. Recently, a meta-analysis concluded that live birth rate was significantly decreased in obese women compared with normal-weight women, with a relative risk of 0.85 (CI 95\%: 0.84-0.87) [15]. Differences in study populations might explain such controversial results, as most published studies were conducted in the US, with different inclusion criteria as regards age and PCOS status. Particularly, results of the latter meta-analysis were largely influenced by two US studies with very large sample size including only fresh embryos [6,12]. Moreover, the reported loss of chance of $15 \%$ yields an absolute chance of giving birth that is acceptable for patients and does not justify refusing access to IVF to obese women. This supports the conclusions of Tremellen et al. that prohibiting obese women's access to IVF may be unfair, as live birth rate in obese women may be far better than that observed for many older women who are allowed access to IVF [23]. In our study, we showed that after 4 cycles, $64 \%$ of obese women gave birth to a child. This rate was similar among overweight, class I and class II/III obesity.

Similarly, the impact of obesity on clinical pregnancy rate is also debated. A meta-analysis showed that clinical pregnancy rate significantly decreased by $13 \%$ in obese women compared to normal-weight women, with however significant heterogeneity in the included studies [24]. On the contrary, other studies found no impact of obesity on clinical pregnancy $[7,25,26]$. It is therefore difficult to be consensual regarding the impact of obesity on IVF prognosis.

On the other hand, weight loss interventions based on nutritional and physical activity changes generally lead to limited weight loss. The impact of most dietary interventions is short-lived and the weight lost is often taken up over time. A randomized controlled trial showed that in women with BMI between 30 and $35 \mathrm{~kg} / \mathrm{m}^{2}$, weight loss did not improve the live birth rate either in the first cycle or after two years, and that regain of pre-study weight occurred in most women of the weight-loss group $[27,28]$. Therefore, these interventions may not only be insufficient but also take some time to allow these obese women to cross BMI thresholds. Further, while age is the main predictor of ARTS success [29], preventing obese women from accessing them can cost them valuable time thus diminishing their chances of conceiving. As regards bariatric surgery, it may be associated with higher risks of small-for-gestational-age infants, shorter length of gestation, and potentially increased risk of stillbirth or neonatal death [30]. Finally, allowing or limiting fertility treatment based on BMI leads to feelings of stigma and injustice, which may in turn sustain failure to lose weight [31]. However, this does not mean that weight loss should not be encouraged.

Further research is required to determine the number of obese women in demand of ART, and to examine the impact of women obesity and its severity on IVF outcomes in larger multicentric cohorts. 
Our work has some limitations, based on a retrospective study with data from register. Some women have to be considered as lost to follow-up, as we do not have any information after the IVF failure. In addition, excluding women with cancelled cycles may have induced selection bias as the proportion of cycle cancellations may differ according to the BMI. Further, women with BMI above 35 $\mathrm{kg} / \mathrm{m}^{2}$ and notably above $40 \mathrm{~kg} / \mathrm{m}^{2}$ were too few to allow analysis regarding grade III obesity. Moreover, we cannot assume that this obese women sample has the same profile as obese women of childbearing age in France, as we do not have any data regarding obese infertile women that did not consult nor for the ones that could not attempt for ART. In particular, some obese women might have been discouraged from attempting ART, even though there is no exclusion criteria based on BMI in our center. One of the main limits of this study is the lack of data regarding complications during pregnancy, as it is well demonstrated that obesity is a major risk factor for gestational complications [32].

\section{Conclusions}

Our study showed that women obesity does not impact the cumulative live birth rate after IVF. Therefore, we do not recommend prohibiting access to ART for obese women. The decision of ART must be integrated into a shared medical decision, while warning women of risks related to obesity.

Supplementary Materials: The following are available online at http://www.mdpi.com/2077-0383/9/8/2414/s1, Table S1: Median rank of embryo transfer to obtain a first live birth; Table S2: Percentages of women with at least one fresh and/or frozen embryo transfer that resulted in live birth by cycle and BMI class; Table S3: Adjusted odd ratios for miscarriage at the first clinical pregnancy by cycle and BMI class.

Author Contributions: Conceptualization, C.B., F.H. and A.S.; methodology, C.B., A.S. and T.M.; software, S.A. and T.M.; validation, A.S. and C.B.; formal analysis, S.A. and T.M.; investigation, A.S.; resources, C.B., N.R. and A.G.; data curation, F.H.; writing-Original draft preparation, A.S. and V.M.; writing-Review and editing, A.S., V.M. and A.A.; visualization, F.H., A.S. and V.M.; supervision, A.S.; project administration, A.S.; funding acquisition, NA. All authors have read and agreed to the published version of the manuscript.

Funding: This research received no external funding.

Acknowledgments: In this section you can acknowledge any support given which is not covered by the author contribution or funding sections. This may include administrative and technical support, or donations in kind (e.g., materials used for experiments).

Conflicts of Interest: The authors declare no conflict of interest.

\section{References}

1. Hassan, M.A.; Killick, S.R. Negative lifestyle is associated with a significant reduction in fecundity. Fertil. Steril. 2004, 81, 384-392. [CrossRef] [PubMed]

2. Wise, L.A.; Rothman, K.J.; Mikkelsen, E.M.; Sorensen, H.T.; Riis, A.; Hatch, E.E. An internet-based prospective study of body size and time-to-pregnancy. Hum. Reprod. 2010, 25, 253-264. [CrossRef] [PubMed]

3. National Institute for Health Care Excellence. Fertility Problems: Assessment and Treatment; NICE: London, UK, 2013.

4. Farquhar, C.M.; Gillett, W.R. Prioritising for fertility treatments-should a high BMI exclude treatment? BJOG 2006, 113, 1107-1109. [CrossRef] [PubMed]

5. RANZCOG (The Royal Australian and New Zealand College of Obstetricians and Gynaecologists). Ovarian Stimulation in Assisted Reproduction; RANZCOG: Melbourne, Australia, 2014.

6. Provost, M.P.; Acharya, K.S.; Acharya, C.R.; Yeh, J.S.; Steward, R.G.; Eaton, J.L.; Goldfarb, J.M.; Muasher, S.J. Pregnancy outcomes decline with increasing body mass index: Analysis of 239,127 fresh autologous in vitro fertilization cycles from the 2008-2010 Society for Assisted Reproductive Technology registry. Fertil. Steril. 2016, 105, 663-669. [CrossRef] [PubMed]

7. Sarais, V.; Pagliardini, L.; Rebonato, G.; Papaleo, E.; Candiani, M.; Vigano, P. A Comprehensive Analysis of Body Mass Index Effect on in Vitro Fertilization Outcomes. Nutrients 2016, 8, 109. [CrossRef] [PubMed]

8. Friedler, S.; Cohen, O.; Liberty, G.; Saar-Ryss, B.; Meltzer, S.; Lazer, T. Should high BMI be a reason for IVF treatment denial? Gynecol. Endocrinol. 2017, 33, 853-856. [CrossRef] [PubMed] 
9. Ding, W.; Zhang, F.L.; Liu, X.C.; Hu, L.L.; Dai, S.J.; Li, G.; Kong, H.J.; Guo, Y.H. Impact of Female Obesity on Cumulative Live Birth Rates in the First Complete Ovarian Stimulation Cycle. Front. Endocrinol. Lausanne 2019, 10, 516. [CrossRef]

10. Bellver, J.; Ayllon, Y.; Ferrando, M.; Melo, M.; Goyri, E.; Pellicer, A.; Remohi, J.; Meseguer, M. Female obesity impairs in vitro fertilization outcome without affecting embryo quality. Fertil. Steril. 2010, 93, 447-454. [CrossRef]

11. Zander-Fox, D.L.; Henshaw, R.; Hamilton, H.; Lane, M. Does obesity really matter? The impact of BMI on embryo quality and pregnancy outcomes after IVF in women aged $\leq 38$ years. Aust. N. Z. J. Obs. Gynaecol. 2012, 52, 270-276. [CrossRef]

12. Kawwass, J.F.; Kulkarni, A.D.; Hipp, H.S.; Crawford, S.; Kissin, D.M.; Jamieson, D.J. Extremities of body mass index and their association with pregnancy outcomes in women undergoing in vitro fertilization in the United States. Fertil. Steril. 2016, 106, 1742-1750. [CrossRef]

13. Provost, M.P.; Acharya, K.S.; Acharya, C.R.; Yeh, J.S.; Steward, R.G.; Eaton, J.L.; Goldfarb, J.M.; Muasher, S.J. Pregnancy outcomes decline with increasing recipient body mass index: An analysis of 22,317 fresh donor/recipient cycles from the 2008-2010 Society for Assisted Reproductive Technology Clinic Outcome Reporting System registry. Fertil. Steril. 2016, 105, 364-368. [CrossRef] [PubMed]

14. Bellver, J.; Pellicer, A.; Garcia-Velasco, J.A.; Ballesteros, A.; Remohi, J.; Meseguer, M. Obesity reduces uterine receptivity: Clinical experience from 9587 first cycles of ovum donation with normal weight donors. Fertil. Steril. 2013, 100, 1050-1058. [CrossRef]

15. Sermondade, N.; Huberlant, S.; Bourhis-Lefebvre, V.; Arbo, E.; Gallot, V.; Colombani, M.; Freour, T. Female obesity is negatively associated with live birth rate following IVF: A systematic review and meta-analysis. Hum. Reprod. Update 2019, 25, 439-451. [CrossRef] [PubMed]

16. Caillon, H.; Freour, T.; Bach-Ngohou, K.; Colombel, A.; Denis, M.G.; Barriere, P.; Masson, D. Effects of female increased body mass index on in vitro fertilization cycles outcome. Obes. Res. Clin. Pr. 2015, 9, 382-388. [CrossRef]

17. Comstock, I.A.; Kim, S.; Behr, B.; Lathi, R.B. Increased body mass index negatively impacts blastocyst formation rate in normal responders undergoing in vitro fertilization. J. Assist. Reprod. Genet. 2015, 32, 1299-1304. [CrossRef] [PubMed]

18. Legge, A.; Bouzayen, R.; Hamilton, L.; Young, D. The impact of maternal body mass index on in vitro fertilization outcomes. J. Obs. Gynaecol. Can. 2014, 36, 613-619. [CrossRef]

19. Pinborg, A.; Gaarslev, C.; Hougaard, C.O.; Nyboe-Andersen, A.; Andersen, P.K.; Boivin, J.; Schmidt, L. Influence of female bodyweight on IVF outcome: A longitudinal multicentre cohort study of 487 infertile couples. Reprod. Biomed. Online 2011, 23, 490-499. [CrossRef]

20. Coyne, K.; Whigham, L.D.; O'Leary, K.; Yaklic, J.K.; Maxwell, R.A.; Lindheim, S.R. Gestational carrier BMI and reproductive, fetal and neonatal outcomes: Are the risks the same with increasing obesity? Int. J. Obes. Lond. 2016, 40, 171-175. [CrossRef]

21. Moragianni, V.A.; Jones, S.M.; Ryley, D.A. The effect of body mass index on the outcomes of first assisted reproductive technology cycles. Fertil. Steril. 2012, 98, 102-108. [CrossRef]

22. Luke, B.; Brown, M.B.; Stern, J.E.; Missmer, S.A.; Fujimoto, V.Y.; Leach, R.; Group, S.W. Female obesity adversely affects assisted reproductive technology (ART) pregnancy and live birth rates. Hum. Reprod. 2011, 26, 245-252. [CrossRef]

23. Tremellen, K.; Wilkinson, D.; Savulescu, J. Should obese women's access to assisted fertility treatment be limited? A scientific and ethical analysis. Aust. N. Z. J. Obs. Gynaecol. 2017, 57, 569-574. [CrossRef] [PubMed]

24. Rittenberg, V.; Seshadri, S.; Sunkara, S.K.; Sobaleva, S.; Oteng-Ntim, E.; El-Toukhy, T. Effect of body mass index on IVF treatment outcome: An updated systematic review and meta-analysis. Reprod. Biomed. Online 2011, 23, 421-439. [CrossRef]

25. Martinuzzi, K.; Ryan, S.; Luna, M.; Copperman, A.B. Elevated body mass index (BMI) does not adversely affect in vitro fertilization outcome in young women. J. Assist. Reprod. Genet. 2008, 25, 169-175. [CrossRef] [PubMed]

26. Ozekinci, M.; Seven, A.; Olgan, S.; Sakinci, M.; Keskin, U.; Akar, M.E.; Ceyhan, S.T.; Ergun, A. Does obesity have detrimental effects on IVF treatment outcomes? BMC Womens Health 2015, 15, 61. [CrossRef] [PubMed] 
27. Einarsson, S.; Bergh, C.; Friberg, B.; Pinborg, A.; Klajnbard, A.; Karlstrom, P.O.; Kluge, L.; Larsson, I.; Loft, A.; Mikkelsen-Englund, A.L.; et al. Weight reduction intervention for obese infertile women prior to IVF: A randomized controlled trial. Hum. Reprod. 2017, 32, 1621-1630. [CrossRef]

28. Kluge, L.; Bergh, C.; Einarsson, S.; Pinborg, A.; Mikkelsen-Englund, A.L.; Thurin-Kjellberg, A. Cumulative live birth rates after weight reduction in obese women scheduled for IVF: Follow-up of a randomized controlled trial. Hum. Reprod. Open 2019, 2019, hoz030. [CrossRef] [PubMed]

29. Nelson, S.M.; Lawlor, D.A. Predicting live birth, preterm delivery, and low birth weight in infants born from in vitro fertilisation: A prospective study of 144,018 treatment cycles. PLoS Med. 2011, 8, e1000386. [CrossRef] [PubMed]

30. Johansson, K.; Cnattingius, S.; Naslund, I.; Roos, N.; Trolle-Lagerros, Y.; Granath, F.; Stephansson, O.; Neovius, M. Outcomes of pregnancy after bariatric surgery. N. Engl. J. Med. 2015, 372, 814-824. [CrossRef]

31. Pandey, S.; Maheshwari, A.; Bhattacharya, S. Should access to fertility treatment be determined by female body mass index? Hum. Reprod. 2010, 25, 815-820. [CrossRef]

32. Catalano, P.M.; Shankar, K. Obesity and pregnancy: Mechanisms of short term and long term adverse consequences for mother and child. BMJ 2017, 356, j1. [CrossRef]

(C) 2020 by the authors. Licensee MDPI, Basel, Switzerland. This article is an open access article distributed under the terms and conditions of the Creative Commons Attribution (CC BY) license (http://creativecommons.org/licenses/by/4.0/). 